J. Lake Sci. (湖泊科学) , 2021, 33(2): 449-461

DOI 10. 18307/2021. 0211

(c) 2021 by Journal of Lake Sciences

\title{
“引江济星”工程及风场环境影响广东肇庆星湖水龄分布特征
}

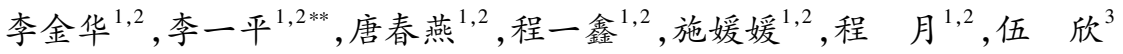 \\ ( 1 : 河海大学浅水湖泊综合治理与资源开发教育部重点实验室, 南京 210098) \\ (2: 河海大学环境学院, 南京 210098) \\ ( 3 : 肇庆市环境保护监测站,肇庆市环境科学研究所,肇庆 526000)
}

\begin{abstract}
摘 要: 目前大量景观类湖泊在人工布局下呈现形状不规整的特点,容易造成湖湾水体滞留形成死水区,水质恶化问题 日益突出, 本文以星湖为研究区域, 建立基于环境流体生态动力学 (EFDC) 模型的星湖水动力一风场耦合模型, 以水龄作 为衡量水体交换速率的指标, 设计 12 种工况模拟计算不同出入湖通道布局及流量配比、“引江济星”工程和风场对星湖 水龄时空分布的影响. 结果表明: 星湖水龄存在季节性和空间性分布差异, 春季主导风向与湖体流动主方向互斥, 抑制了 波海湖水体交换, 导致水龄在春季较长, 而秋季南西南季风促进中心湖等水体交换, 致使水龄偏短, 也反映出风向的影响 存在湖区空间异质性, 风向为南东南时星湖整体水龄最小; 人湖口通道布局及流量配比对湖区水体交换速率存在影响, 以外坑为波海湖人湖口且波海湖、中心湖、仙女湖人流比为 $4: 3: 3$ 时, 星湖整体水龄最小, 拟建的青莲湖出水口和仙女湖 出水口能有效加快青莲湖东北部和仙女湖东南部的水体交换速率; 综合考虑调水引流效益、经济投资、生态开发和占地 的成本, 方案二为最优调水引流方案. 本研究强调人湖口布局、流量大小和比例、及风场等因素对城市内湖水体置换的影 响, 为人为干扰下的景观湖泊的治理和管控提供科学支撑.
\end{abstract}

关键词: 星湖;水龄;EFDC 模型; “引江济星”工程;风场

\section{Water age distribution characteristics of Lake Star (Zhaoqing, Guangdong) influenced by the Water Diversion Project and wind field*}

\author{
Li Jinhua $^{1,2}$, Li Yiping ${ }^{1,2 * *}$, Tang Chunyan ${ }^{1,2}$, Cheng Yixin ${ }^{1,2}$, Shi Yuanyuan ${ }^{1,2}$, Cheng Yue ${ }^{1,2} \& \mathrm{Wu} \mathrm{Xin}^{3}$ \\ (1: Key Laboratory of Integrated Regulation and Resource Development on Shallow Lakes, Ministry of Education, Hohai Uni- \\ versity, Nanjing 210098, P.R.China) \\ (2: College of Environment, Hohai University, Nanjing 210098, P.R.China) \\ (3: Environmental Protection Monitoring Station, Institute of Environmental Science, Zhaoqing 526000, P.R.China)
}

\begin{abstract}
At present, a large number of Landscape lakes have the characteristics of irregular shape under the artificial layout, which is easy to cause bay water retention and form dead zones. The water quality deterioration is increasingly prominent. This paper takes Lake Star as the research area, based on EFDC (environmental fluid dynamics code) model that hydrodynamic-wind field coupling model was set up, the water age is taken as the index to measure the water exchange rate, 12 working conditions were designed to calculate the influence of different access points and flow ratio, Water Diversion Project from the West River to Lake Star and wind field on the spatial and temporal distribution of water age in Lake Star. The result shows that: there are seasonal and spatial distribution differences in the water age of Lake Star. The dominant wind direction in spring and the main flow direction of the lake are mutually exclusive, which restrained the water exchange with Lake Bohai, resulting in a longer water age in spring. The south-southwest monsoon in autumn promotes the water exchange of Lake Central and other water bodies, resulting in a shorter water age, which also reflects the influence of wind direction on the spatial heterogeneity of the lake area. When the wind direction is southeast, the water age of Lake Star is the smallest; the channel layout and flow ratio have influence on the water exchange rate in
\end{abstract}

* 2020-04-21 收稿;2020-07-01 收修改稿.

国家重点研发计划项目 (2017YFC0405203,2016YFC0401703)、中央高校建设世界一流大学(学科)和特色发展引 导专项资金项目和国家自然科学基金项目 $(51779072,51809102)$ 联合资助.

** 通信作者;E-mail:liyiping_hhu@163.com. 
the lake area, the outer pit is the entrance of Lake Bohai and when the inflow ratio of Lake Bohai, Lake Central and Lake Xiannv is $4: 3: 3$, the overall water age of Lake Star is the smallest, the proposed outlets of Lake Qinglian and Lake Xiannv can effectively accelerate the water exchange rate in the northeast of Lake Xiannv and southeast of Lake Qinglian; comprehensive study considering the benefit of water diversion, economic investment, cost of ecological development and land occupation, the second scheme is the optimal water diversion scheme. This study emphasizes the influence of the layout of the lake entrance, the size and proportion of the flow, and the wind field on the water replacement of the municipal lakes, which provides scientific support for the management and control of the landscape lakes under human disturbance.

Keywords: Lake Star; water age; Water Diversion Project from the West River to Lake Star; EFDC model; wind field

城市景观湖泊通常兼具景观生态、接纳雨污、储蓄调洪等多种功能 ${ }^{[1]}$, 由于地处人口相对密集的区域, 周边分布着复杂的小区、工厂、商户,城市景观湖泊的水质往往更容易受到人为排污等活动的影响,生态环 境十分脆弱, 加之此类湖泊水系连通性差, 缺少补水源水, 出入流河道、闸门较少, 湖泊相对封闭, 导致湖泊 换水周期较长. 城市景观湖泊在人为布局下往往呈现形状不规整的特点, 容易使湖湾水体滞留形成死水区, 在夏季高温时期, 藻类极易滋生堆积形成水华, 湖泊水体健康面临严重危机 ${ }^{[2]}$. 星湖位于广东省肇庆市, 是 国家级重点风景名胜区, 近年来星湖富营养化问题日益加剧, 为改善部分湖区水体流通性差、水质不达标的 现状, 肇庆市政府提出 “一滴污水不进星湖”, 并对星湖周边排污口、排水沟实行严格的控源截污, 同时为缩 短星湖换水周期, 改善星湖水质, 提升星湖水体透明度, 提出了 “引江济星” 工程, 即引西江水和北岭山山水 进人星湖.

对于大型湖泊而言, 人湖流量和风场在驱动湖泊水体运动和水动力交换过程中发挥着重要的作用, 水 龄作为衡量水体交换速率的重要指标, 已有大量关于水龄研究的成果. $\mathrm{Li}$ 等 ${ }^{\left[{ }^{3}\right]}$ 引人水龄的概念, 分析 “引江 济太” 工程引水量对太湖水动力调控效果的影响, 研究表明太湖水体的输移过程受出人流水动力条件和风 场的强烈影响; Gao 等 ${ }^{[4]}$ 研究了引水工程对人为布局下的城市人工湖水龄的影响, 揭示了引水量和湖区布局 与水体交换速率间的关系, 并基于 EFDC 模型模拟了风场及水位对七里海泻湖水体更新能力的影响 ${ }^{[5]}$, 发 现东北风显著提升了七里海泻湖的水体更新能力; 王钟等 ${ }^{[6]}$ 分析 “引江济淮”工程和风应力对蔡子湖水龄分 布的影响, 结果表明: 风应力对蔡子湖水龄分布有重要影响; 黄春琳等 ${ }^{[7]}$ 基于 EFDC 模型研究“引江济太”工 程对太湖水龄分布的影响; 张素香等 ${ }^{[8]}$ 构建鄱阳湖染色剂和水龄模型,计算不同人流河道对湖区的影响,论 证了鄱阳湖水利枢纽工程调水方案的合理性; 戚文等 ${ }^{[9]}$ 利用 EFDC 模型建立天镜湖的三维非稳态水量、水 龄、污染物颗粒追踪数学模型. 此外, 通过建立水龄和水质的相关关系, 可便于明晰水体中营养盐含量与水 龄的联系;Zhang 等 ${ }^{[10]}$ 构建三维水动力水质耦合模型, 分析牛栏山引水工程对滇池水龄和水质的影响, 发现 滇池水龄的大小与总磷浓度呈正相关, 与总氮、叶绿素 $a$ 浓度无明显相关性. 以上研究虽然都取得了很多有 意义的成果, 但大多是针对引调水工程、风场或季节变化对大型湖泊水体输移速率方面的研究, 涵概因素单 一, 特别是针对南方季风气候区城市景观湖泊, 缺少全面考虑进出水通道布局、流量配比及风场对工程效益 的影响等方面的研究.

近年来, 随着引调水工程在西湖 ${ }^{[11]}$ 、太湖、滇池的成功运用, 调水引流已经作为提升湖泊水体交换速率、 改善湖泊水质的重要措施之一 ${ }^{[12]}$, 本研究以南方季风气候地区典型城市景观湖泊一一星湖为例, 以 EFDC 模型为工具, 基于实测风场、水位和地形数据以及基于湖泊水量平衡换算的流量数据构建星湖三维水动 力一风场耦合模型, 综合考虑季节变化、风场、调水引流工程对星湖水龄时空分布的影响, 并结合实际情况, 对进水线路和进水比例进行优化, 全面考虑引调水工程的效益、经济投资、生态占地和生态开发等各个方 面, 遴选最优引调水方案、最佳调水季节和风向, 从水动力的角度模拟星湖在不同调水引流情景下以及不同 风向下星湖水龄的时空分布情况, 以提供星湖平均水龄较低的最优调水引流方案, 为 “引江济星”工程的实 施管理提供科学依据.

\section{1 研究区域及方法}

\section{1 研究区域概况}

星湖 ( $23^{\circ} 3^{\prime} 27^{\prime \prime} \sim 23^{\circ} 5^{\prime} 15^{\prime \prime} \mathrm{N}, 112^{\circ} 26^{\prime} 38^{\prime \prime} \sim 112^{\circ} 29^{\prime} 20^{\prime \prime} \mathrm{E}$ ) 位于广东省肇庆七星岩风景区内, 北倚北岭山, 
南接端州城区, 地处南亚热带, 年均温度 $21.2^{\circ} \mathrm{C}$, 气候温暖湿润, 属于季风气候, 且降水主要集中在 $4-9$ 月, 年平均降水量约 $1650 \mathrm{~mm}, 2018$ 年全年主导风向为西南风, 年平均风速约 $1.25 \mathrm{~m} / \mathrm{s}$, 星湖为城市内景观湖 泊, 平均水深为 $2.34 \mathrm{~m}$, 最大水深为 $3.65 \mathrm{~m}$, 总面积约为 $5.82 \times 10^{6} \mathrm{~m}^{2}$ (相应水位为 $4.91 \mathrm{~m}$ ), 总容积约为 $13 \times$ $10^{6} \mathrm{~m}^{3}$, 目前星湖水生植物较少, 常见水生植物约 15 种, 其中沉水植物仅有 4 种, 群落结构简单 ${ }^{[13]}$.

星湖由波海湖、中心湖、青莲湖、仙女湖、里湖五大湖区组成( 图 1), 其中波海湖、仙女湖、中心湖和青莲 湖通过桥涵互相连通, 水可以自由流动, 补水源水由北部及周边集水区的涝水和北岭截洪渠的山洪溢流提 供, 里湖相对封闭, 主要由湖面降雨和中心湖补给水量, 且与其他湖区存在约 $1 \mathrm{~m}$ 的水位落差, 本文以波海 湖、中心湖、青莲湖、仙女湖 4 个子湖区为主要研究对象, 由于自然条件下里湖与其它 4 个子湖区互不存在水 体交换, 故暂不考虑引水工程及风场对里湖水龄分布的影响. 星湖的主要人湖口为外坑 A 1 、盘古坑 $\mathrm{A} 2$ 、石牌 坑 A3 以及概化的雨水口 B1、排污口 B2、排污口 B3, 主要出水口为中心湖南部的牌坊换水涵 $\mathrm{C} 1$ 、青莲湖东南 部的芹田水闸 C 2 以及仙女湖北部的东岗节制闸 C5, 青莲湖出水口 C3 和仙女湖出水口 C4 为规划拟建的出 水口.

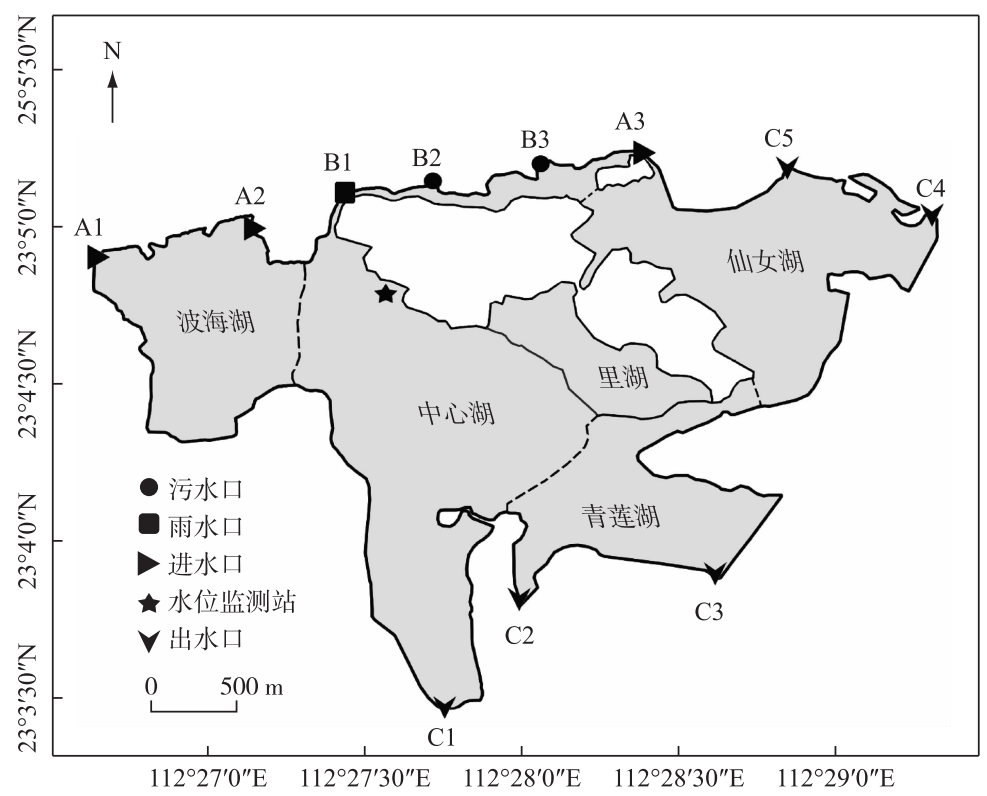

图 1 研究区域概况

Fig. 1 Map of the study area

\section{2 模型的构建及率定验证}

1.2.1 模型构建 EFDC 模型最早由美国美国弗吉尼亚大学和海洋科学研究所开发,应用笛卡尔坐标或曲线 正交坐标系统 ${ }^{[14]}$, 在空间上运用二阶精度有限差分格式, 水平扩散方程采用时间显示、空间隐式格式, 水平 输运方程采用 Blumberg-Mellor 模型的中心差分格式或者正定迎风差分格式 ${ }^{[15]}$. 被广泛应用于河流 ${ }^{[16]}$ 、湖 泊 $^{[17]}$ 、湿地 ${ }^{[18]}$ 、河口 ${ }^{[19]}$ 以及水库 ${ }^{[20]}$ 的水动力、水质和水生态模拟中, 能够动态展现三维水动力及污染物迁 移扩散的轨迹. 本文将 EFDC 模型应用于星湖的水动力模拟研究中, 构建三维水动力模型, 在水平上采用笛 卡尔直角坐标系, 垂向上采用 Sigma 坐标, 水平网格数共计 2212 个, 网格空间分辨率为 $52 \mathrm{~m}$, 垂向分为 3 层, 每层厚度由水面高度和湖底地形决定. EFDC 模型以风速、风向、人湖流量、出湖水位为水动力模块的边界条 件, 其中人湖边界为 3 条排水坑 (外坑、盘古坑、石牌坑)、6 个排污口和 1 个雨水口, 出湖边界包括 3 个出水 闸门(牌坊换水涵、芹田水闸和东岗节制闸).

由 4215 个实测点位高程数据内插形成星湖底部地形,初始水位为 2018 年 1 月 1 日星湖水位监测站实 测水位 (4.88 m), 四季风速 (图 2) 数据采用 2018 年实测值(数据来源: http://data.cma.cn/), 模拟时间 2018 
年 1 月 1 日一 12 月 31 日,动态时间步长取 $0.5 \mathrm{~s}$. 为了适应水位波动, 尤其是相对浅水区域, 模型设置临界干 水深 $0.05 \mathrm{~m}$.

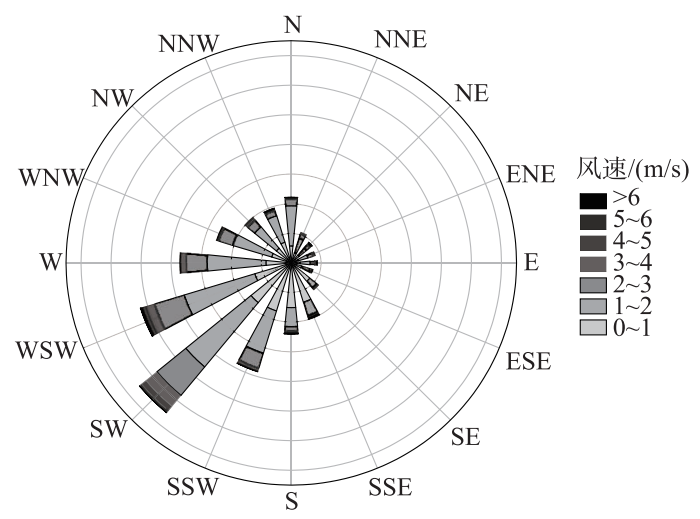

图 2 星湖 2018 年风玫瑰图

Fig. 2 Wind rose of Lake Star in 2018

1.2.2 模型率定验证 模型中的参数取值会对模拟结果产生重要的影响, 本研究重点率定风场参数及底部粗 粮系数, 最终取糙率参数为 0.02 , 风拖曳系数为 $3 \times 10^{-3}$, 风遮挡系数为 1 . 通过对星湖水位监测点位 2018 年 全年的模拟值与实测值比较可知 (图 3), 星湖水位的绝对误差为 $0.007 \mathrm{~m}$, 均方根误差为 $4.4 \%$, 选取 2017 年 星湖水位监测站实测水位及基于水位平衡换算的出人流量数据作为模型的验证数据, 模拟值与实测值比较 可知 (图 3), 2017 年星湖水位绝对误差为 $0.024 \mathrm{~m}$,均方根误差为 $3.4 \%$, 模拟值与实测值误差较小且吻合较 好, 说明模型的模拟结果能较好地反映星湖的水位变化情况.

1.2.3 水龄的定义 本研究利用水龄和拉格朗日颗粒物追踪的概念来描述湖体交换快慢及交换程度, 获取最 佳调水流量、调水时机, 提出多种改善湖体水龄、加速水体交换的有效组合.

水龄模型是基于对流扩散模型发展起来, 用于衡量湖泊和水库污染物迁移的有效参数 ${ }^{[21]}$. 水龄定义 为: 对单个粒子来说, 粒子从进人水体到达指定位置所需的时间. 针对不同的研究问题, 水龄可以定义为不 同的形式. 例如研究水体垂向交换时,水龄定义为水体离开水体表面,到达垂向某一位置所需的时间; 当研 究水体与外部水体交换时可定义为颗粒物从人口传输到指定点的时间 (往往人口的水龄设为零). 水龄能够 反映出水质点或者污染物从边界传输到研究区域内任何一点的时间, 定量反映出水体交换能力的时间和空 间异质性, 定性反映污染物传输特征和水体富营养化程度. 水龄越小, 说明水体交换程度越强, 反之亦然. 水 龄计算公式如下:

$$
\begin{gathered}
\frac{\partial c(t, \vec{x})}{\partial t}+\nabla(u \cdot c(t, \vec{x})-K \nabla c(t, \vec{x}))=0 \\
\frac{\partial \alpha(t, \vec{x})}{\partial t}+\nabla(u \cdot \alpha(t, \vec{x})-K \nabla \alpha(t, \vec{x}))=c(t, \vec{x})
\end{gathered}
$$

式中, $c$ 为示踪剂浓度 $(\mathrm{mg} / \mathrm{L}), \alpha$ 为水龄初始设置值 $(\mathrm{d}), u$ 为流速 $(\mathrm{m} / \mathrm{s}), K$ 为扩散张量, $t$ 为时间 $(\mathrm{s}), \vec{x}$ 为 坐标. 水龄 $a$ 可根据下式计算:

$$
a(t, \vec{x})=\frac{\alpha(t, \vec{x})}{c(t, \vec{x})}
$$

1.2.4 计算方案 为确定人湖口通道布局、人湖流量分配比例、出入湖口数量以及风场对星湖水龄的影响, 本 文共设计 4 个方案共计 12 种工况 (表 1) 进行计算. 星湖是典型的城景观湖泊, 湖区面积较小, 工况 1 和工况 $1^{0}$ 分别计算现状情景下有风和无风时星湖的水龄分布,并基于实测气象数据模拟星湖水龄的季节性变化规 律, 方案一、方案二和方案三分别计算了不同引调水方案下星湖的水龄空间分布, 其中工况 $3 、 4 、 5 、 7 、 8 、 9$ 计 算不同人湖口位置分布和人湖流量比例情景下星湖水龄空间分布, 工况 6 模拟拟建的青莲湖出水口和仙女 湖出水口对星湖水龄的影响, 工况 $6^{1 \sim 16}$ 则模拟恒定风速, 16 种不同风向下星湖水龄的时空分布特征. 

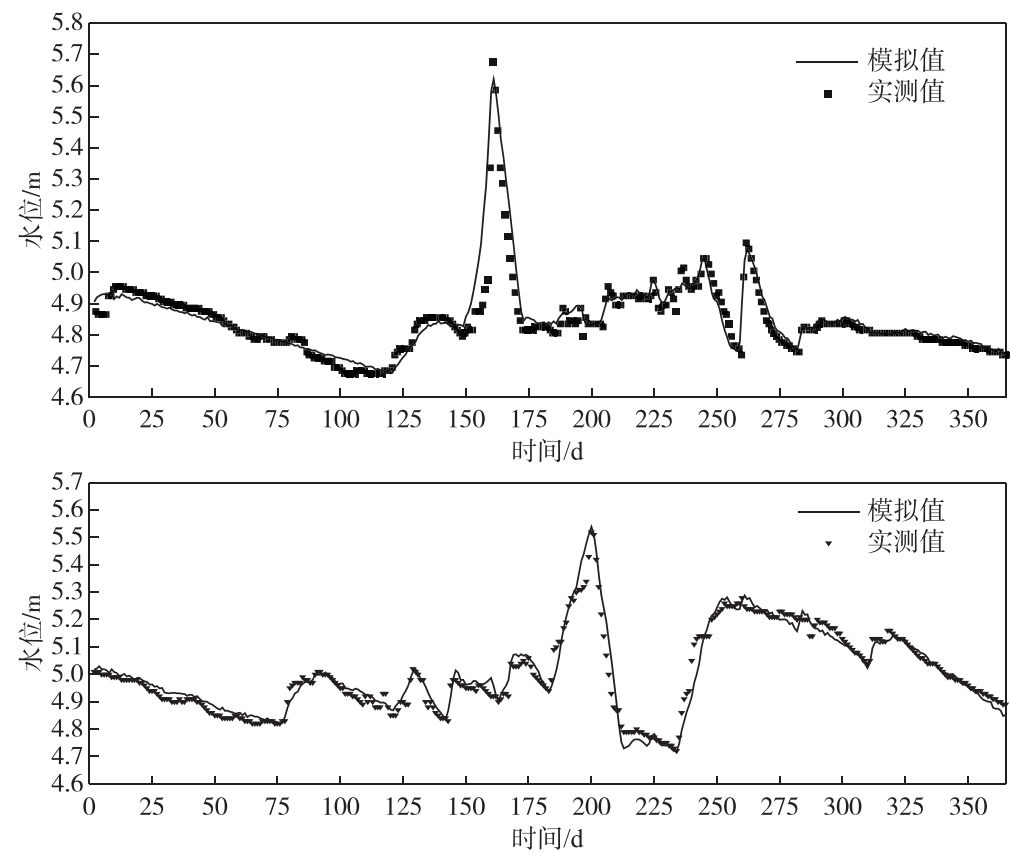

图 3 星湖水动力模型率定 (2018 年)和验证(2017 年)结果(珠基高程)

Fig.3 Calibration(2018) and verification(2017) results of the hydrodynamic model of Lake Star (Pearl River elevation reference)

表 1 模型计算方案 “

Tab.1 Model calculation scenarios

\begin{tabular}{|c|c|c|c|c|c|}
\hline 方案 & 工况 & $\begin{array}{c}\text { 人波海湖 } \\
q 1 /\left(\mathrm{m}^{3} / \mathrm{s}\right)\end{array}$ & $\begin{array}{c}\text { 人中心湖 } \\
q 2 /\left(\mathrm{m}^{3} / \mathrm{s}\right)\end{array}$ & $\begin{array}{c}\text { 人仙女湖 } \\
q 3 /\left(\mathrm{m}^{3} / \mathrm{s}\right)\end{array}$ & $\begin{array}{l}\text { 出湖口 } \\
\text { 数量 }\end{array}$ \\
\hline \multirow[t]{2}{*}{ 现状 } & 1 & $0 \sim 2.31^{1)}$ & $0.0949 \sim 0.35^{2)}$ & $0.0949 \sim 0.35^{2)}$ & 2 \\
\hline & $1^{0}$ & $0 \sim 2.31$ & $0.0949 \sim 0.35$ & $0.0949 \sim 0.35$ & 2 \\
\hline 方案一:北岭山来水 & 2 & 0.494(经盘古坑) & - & 0.494 & 3 \\
\hline \multirow[t]{8}{*}{ 方案二:西江引水 } & 3 & 1.4(经盘古坑) & 2.95 & 1.65 & 3 \\
\hline & 4 & $1.4($ 经外坑 $)$ & 2.95 & 1.65 & 3 \\
\hline & 5 & $2.4(40 \%)$ (经外坑) & $1.8(30 \%)$ & $1.8(30 \%)$ & 3 \\
\hline & $6^{1 \sim 16}$ & $2.4(40 \%)$ (经外坑) & $1.8(30 \%)$ & $1.8(30 \%)$ & 3 \\
\hline & 6 & $2.4(40 \%)$ (经外坑) & $1.8(30 \%)$ & $1.8(30 \%)$ & 5 \\
\hline & 7 & $2.4(40 \%)$ (经外坑) & $2.4(40 \%)$ & $1.2(20 \%)$ & 3 \\
\hline & 8 & $2.0(33 \%)$ (经外坑) & $2.0(33 \%)$ & $2.0(33 \%)$ & 3 \\
\hline & 9 & $1.8(30 \%)$ (经外坑) & $2.4(40 \%)$ & $1.8(30 \%)$ & 3 \\
\hline 方案三:西江引水+北岭山来水 & 10 & 2.72 & 2.04 & 2.04 & 3 \\
\hline
\end{tabular}

$* 1^{0}$ : 现状无风情景; 1) :2018-01-01-2018-12-31 时间段估算值;2) : 多年平均经验值; $6^{1 \sim 16}$ : 风速为 $2 \mathrm{~m} / \mathrm{s}$, 风向分别为 $N, N N E, N E, E N E, E, E S E, S E, S S E, S, S S W, S W, W S W, W, W N W, N W, N N W$; 出湖口 2 个是指: 东岗节制闸、芹田水闸; 出湖口 3 个指: 牌坊换水涵、芹田水闸、东岗节制闸; 出湖口 5 个指: 牌坊换水涵、芹田水闸、东岗节制闸、青莲湖出水口( 拟建)、仙 女湖出水口 (拟建); 一表示无对应数据. 


\section{2 结果与讨论}

\section{1 星湖水龄时空分布特征及风场对水龄分布的影响}

现状情景下工况 1 和工况 $1^{0}$ 分别计算了有风和无风情景下星湖水龄的季节性分布情况 (图 4), 在无风 情景下水龄的季节性变化从小到大依次为: 秋季 $(123.95 \mathrm{~d})$ <夏季 $(131.89 \mathrm{~d})<$ 冬季 $(155.21 \mathrm{~d})<$ 春季 $(182.23$ $\mathrm{d})$, 而有风情景下四季水龄从小大依次为:秋季 $(96.63 \mathrm{~d})<$ 夏季 $(114.78 \mathrm{~d})<$ 冬季 $(142.42 \mathrm{~d})<$ 春季 $(179.77$ d), 较无风情景而言, 有风情景下星湖春、夏、秋、冬季整体平均水龄分别降低了 $2.46 、 17.11 、 27.31 、 12.78 \mathrm{~d}$, 主要原因是秋季人流流量大, 且秋季主导风向与湖流运动方向相近, 利于水体交换, 而春、冬季节出人流流 量小, 水体交换速率较弱; 由于湖区边界形状差异, 水龄的季节变化在湖区空间分布上也有显著区别, 对比 无风情景, 有风情景下中心湖、青莲湖、仙女湖水龄分别降低了 $52.37 、 11.65 、 43.95 \mathrm{~d}$, 波海湖水龄反而增加了 $21.6 \mathrm{~d}$, 主要是因为波海湖南、西、北三面为岸线形成 “小湖湾”, A $1 、 \mathrm{~A} 2$ 两个人流口与风向相悖, 唯一的出流 口仅为波海湖与中心湖中间的相通桥涵, 因此主导风抑制了波海湖的水体交换, 而中心湖、青莲湖和仙女湖 的水体交换受到风场正向驱动. 夏、秋季风(西南风)作用提升了星湖的水体交换速率, 而春季季风(南西南 风) 对星湖的水龄分布影响较小.
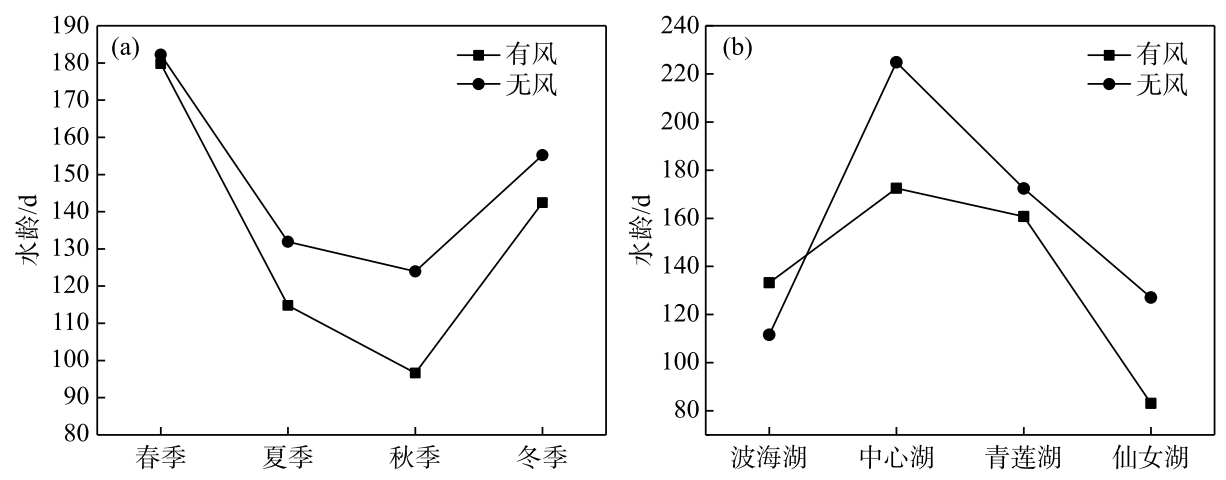

图 4 星湖水龄季节性差异 (a) 和空间分布差异 $(b)$

Fig.4 Seasonal (a) and spatial (b) variations of water age in Lake Star

对于大型浅水湖泊, 风应力是湖泊形成环流的主要驱动力之一, 分析不同风向下湖泊水龄的时空分布 特征可以更好地论证调水引流工程对湖泊水体交换速率的改善效益, 同时, 水龄的时空分布也可以作为评 估调水引流对湖泊水质改善效益的重要参考指标.

研究中模拟了恒定风速 $2 \mathrm{~m} / \mathrm{s}$ 时 16 种不同风向下、以及强风向 (南东南风)下不同风速时星湖湖体水 龄的时空分布, 计算了波海湖、中心湖、青莲湖以及仙女湖在不同风向下的水龄, 计算结果见图 5. 模拟结果 表明:在相同风速、不同风向下, 南东南风对星湖整体水龄的改善最为显著 (湖区整体平均水龄为 $19.95 \mathrm{~d}$ ), 北东北风对水体交换的影响最弱 (湖区整体平均水龄为 $27.76 \mathrm{~d}$ ), 不同子湖区的影响结果也有很大的差异, 青莲湖是水龄最大的湖区, 仙女湖是受风场影响最小的湖区 ( 16 个风向下水龄在 $13.52 \sim 21.54 \mathrm{~d}$ 之间), 这 表明靠近引水点区域的水体最先被交换, 其它区域在不同风向情景下呈现不同的差异, 波海湖平均水龄范 围为 $6.53 \mathrm{~d}$ (南风) 21.54 d (西西北风); 中心湖平均水龄范围为 $16.89 \mathrm{~d}$ (南西南风) $27.93 \mathrm{~d}$ (东北风); 青 莲湖平均水龄范围为 $39.86 \mathrm{~d}$ (西风) $~ 63.46 \mathrm{~d}$ (北风); 仙女湖平均水龄范围为 $13.52 \mathrm{~d}$ (西南风) $21.54 \mathrm{~d}$ (北 风).

在南东南风(强风向) $0 、 2 、 4 、 6 \mathrm{~m} / \mathrm{s}$ 风速下, 星湖平均水龄分别为 $18.44 、 19.95 、 18.18$ 和 $18.35 \mathrm{~d}$, 对于同 一湖区, 由风向差异引起的水龄的最大差值为 $34.38 \mathrm{~d}$ (波海湖), 最小为 $8.03 \mathrm{~d}$ (仙女湖), 不同湖区在对同一 风向 (南东南风) 不同风速下水龄的表现也有所差异, 最小为 $2.50 \mathrm{~d}$ (波海湖), 最大为 $26.31 \mathrm{~d}$ (青莲湖); 不 同风向对星湖整体水龄的影响在 $0.02 \sim 7.81 \mathrm{~d}$ 之间, 因此风场对星湖水龄时空分布影响较小. 研究结果表 明:不同风向对星湖各个湖区的改善效果不同,南风有助于波海湖的水体交换,南西南风有助于中心湖的水 
体交换, 西西南风有助于青莲湖的水体交换, 东风有助于仙女湖的水体交换, 而对于星湖整体而言, 风向为 南东南风时水龄较小, 表明南东南风是 “引江济星”工程提升星湖换水速率和改善水质最有效的风向.
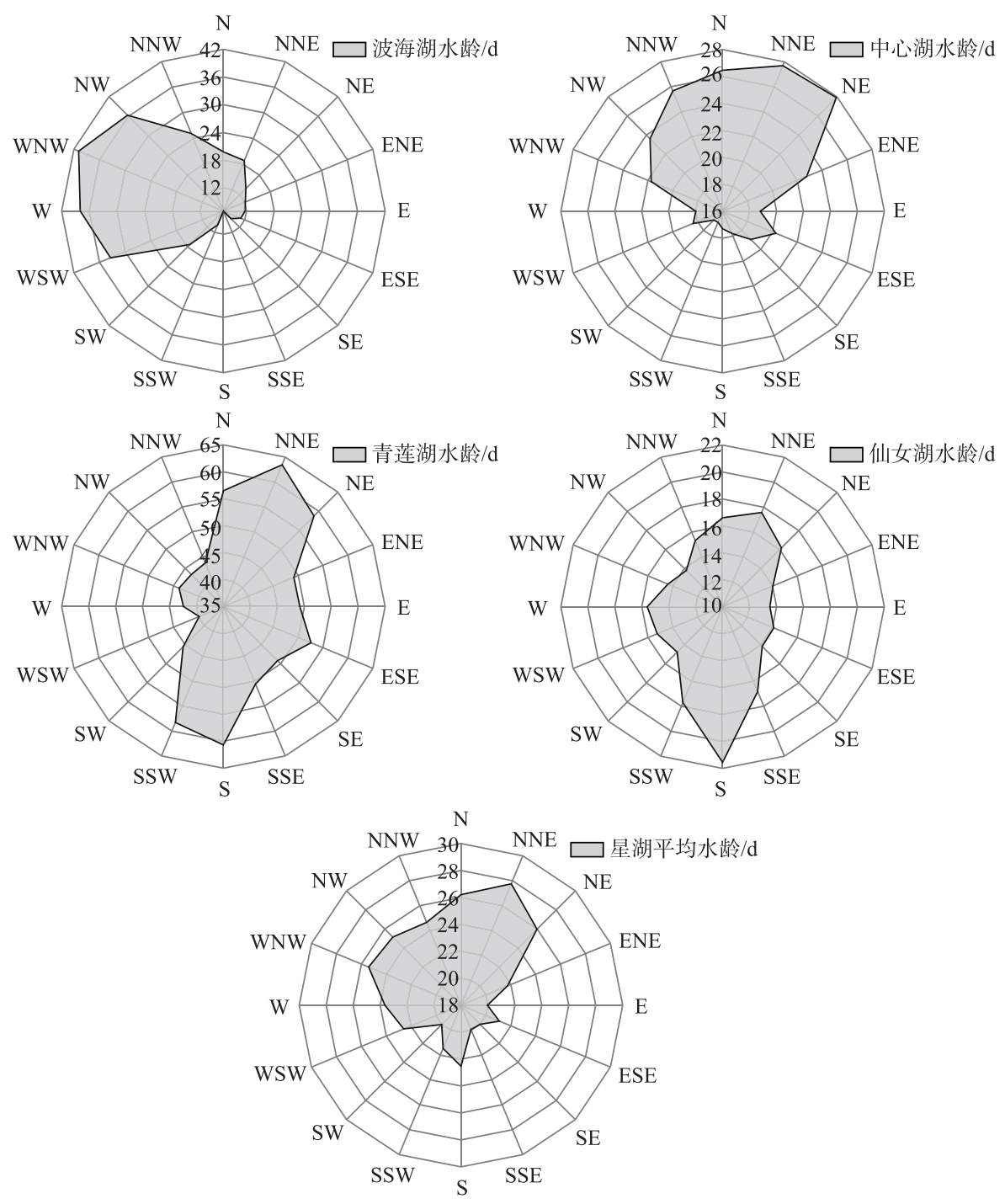

图 5 各湖区水龄受风向影响情况

Fig.5 Spatial distribution of water age in each lake district

\section{2 不同出入湖点位设置及入流配比情景下水龄分布特征}

为了进一步明晰不同人湖通道布局以及配水比例下 “引江济星”工程对星湖水龄的影响, 结合星湖现有 进水通道和 “引江济星” 工程拟规划设计 3 个进水口, 对于波海湖人湖口的选择, 一是由外坑直接人波海湖, 二是新建输水管道后由盘古坑人波海湖, 其人湖点需进一步评估, 其余人中心湖和仙女湖的点位相对明确; 补水进人星湖后, 通过芹田水闸、牌坊换水涵和东岗节制闸 3 处向外排水,星湖形成“三进三出” 的水体交换 格局, 让星湖各个湖区的水体得到充分交换, 减少死水区面积, 通过增强水体循环来改善水质, 由模拟结果 可知, 经外坑人波海湖的配水点位设置要略优于经盘古坑人湖的路线, 其中波海湖的改善效果尤为显著, 波 海湖水龄由 $68 \mathrm{~d}$ 降至 $43 \mathrm{~d}$, 水体交换速率提高了 $37 \%$, 但对其它湖区影响甚微.

此外,进水口的配水比例也会对湖泊水体交换产生一定的影响,本文模拟了 4 种配水比例工况下 “引江 
济星”工程对星湖水动力的影响, 结果表明:工况 5 为最优方案, 即波海湖人湖口、中心湖人湖口、仙女湖人 湖口的配水比例为 $4: 3: 3$ 时星湖整体水龄最低, 此时波海湖、中心湖、青莲湖、仙女湖以及星湖整体平均水龄 分别为 $42.79 、 33.20 、 73.28 、 28.25$ 和 $37.40 \mathrm{~d}($ 表 2$)$.

表 2 不同工况下各湖区水龄统计

Tab.2 Water age statistics of each lake area under different working conditions

\begin{tabular}{cccccc}
\hline \multirow{2}{*}{ 工况 } & \multicolumn{3}{c}{} & \multicolumn{2}{c}{ 水龄 $/ \mathrm{d}$} \\
\cline { 2 - 5 } & 波海湖 & 中心湖 & 青莲湖 & 仙女湖 & 星湖均值 \\
\hline 4 & 68.31 & 32.75 & 69.72 & 28.23 & 40.92 \\
5 & 42.79 & 33.20 & 73.28 & 28.25 & 37.40 \\
6 & 23.70 & 30.40 & 73.70 & 29.70 & 33.30 \\
7 & 23.20 & 29.21 & 79.20 & 33.50 & 34.40 \\
8 & 27.64 & 32.08 & 75.80 & 26.97 & 34.16 \\
9 & 28.17 & 32.21 & 72.50 & 27.62 & 34.13 \\
\hline
\end{tabular}

\section{3 不同引调水方案下星湖水龄分布特征}

为评估不同工况下 “引江济星” 工程对星湖水动力的改善效果, 基于最优人湖通道布局以及最优人湖流 量比例, 模拟 3 种调水引流方案下星湖的水龄分布情况, 即方案一: 北岭山来水 $\left(q=0.988 \mathrm{~m}^{3} / \mathrm{s}\right)$, 方案二: 西 江引水 $\left(q=6 \mathrm{~m}^{3} / \mathrm{s}\right)$, 方案三: 北岭山来水+西江引水 $\left(q=0.988 \mathrm{~m}^{3} / \mathrm{s}+5.8 \mathrm{~m}^{3} / \mathrm{s}\right)$, 方案一充分考虑北岭山山洪 和降雨资源, 通过新修截洪渠和集水池收集水资源, 并利用现有进水坑道 (盘古坑和石牌坑) 对星湖实施补 水; 方案二从西江引水, 通过修建引配水管道达到合理分配引水资源、盘活星湖水体和提升星湖换水速率的 目的; 方案三综合考虑利用北岭山山洪、降雨资源和西江引水资源. 星湖现阶段主要通过牌坊换水涵、芹田 水闸和东岗节制闸向外排水, 另有两处规划建设排水口, 即青莲湖出水口和仙女湖出水口, 本研究在评估 “引江济星”工程对星湖水动力改善的过程中, 假定: 1) 忽略风场的影响;2) 各个工况除人、出湖边界条件 (边界位置及人流流量) 等不同之外,其它条件及参数设定均相同, 模型模拟时长为 $365 \mathrm{~d}$.

基于水动力一风场耦合模型得出的不同引调水工况下星湖的水龄空间分布 (图 6 图 9), 颜色为蓝色代 表水龄越小, 颜色为红色则说明该点水龄越大, 模拟结果表明, 人湖流量与水龄呈反比, 即随着流量的提升, 湖区整体水龄水龄越小, 且随着流量的增加, 4、15、30、60 d 等水龄线分布范围不断增加 (表 3). 其中方案三 为降低湖区水龄值的最优调水引流方案 (工况 10), 方案二次之 (工况 5), 方案一对星湖的水龄改善效果最 差 (工况 1), 三种工况下星湖水龄均值分别为 $30.62 、 33.30 、 106.70 \mathrm{~d}$, 表明 “引江济星”工程可以加快星湖的 水体交换速率, 减小星湖水龄, 特别针对波海湖、中心湖和仙女湖中北部, 水体交换速率有很大的提升, 但青 莲湖仍存在水体交换速率较差的区域,而青莲湖东部恰是藻类暴发的高发区.

表 3 不同工况下水龄区间所占湖区面积

Tab.3 The area covered by different working conditions of water age

\begin{tabular}{ccccc}
\hline \multirow{2}{*}{ 工况 } & \multicolumn{3}{c}{ 面积 $/ \mathrm{km}^{2}$} \\
\cline { 2 - 5 } & $0 \sim 4 \mathrm{~d}$ 水龄 & $4 \sim 14 \mathrm{~d}$ 水龄 & $14 \sim 29 \mathrm{~d}$ 水龄 & 大于 $29 \mathrm{~d}$ 水龄 \\
\hline 现状情景 & 0.34 & 0.20 & 0.92 & 0.02 \\
方案一 & 0.57 & 0.35 & 2.53 & 0.22 \\
方案二 & 0.95 & 2.15 & 1.73 & 0.29 \\
方案三 & 1.47 & 2.98 & 1.07 & 0.05 \\
\hline
\end{tabular}

为减少青莲湖东部和仙女湖东部 “死水区”的分布范围, 降低水华的暴发风险, “引江济星”工程规划拟 建青莲湖出水口和仙女湖出水口, 其建设的效果和必要性仍需进一步评估, 工况 6 模拟了新增青莲湖出水 口和仙女湖出水口对青莲湖和仙女湖的水龄改善, 结果表明, 工况 6 情景下青莲湖和仙女湖水龄分别为 30.45 和 $12.92 \mathrm{~d}$, 工况 5 情景下青莲湖和仙女湖水龄分别为 73.70 和 $33.30 \mathrm{~d}$, 较工况 5 而言, 工况 6 情景下青 

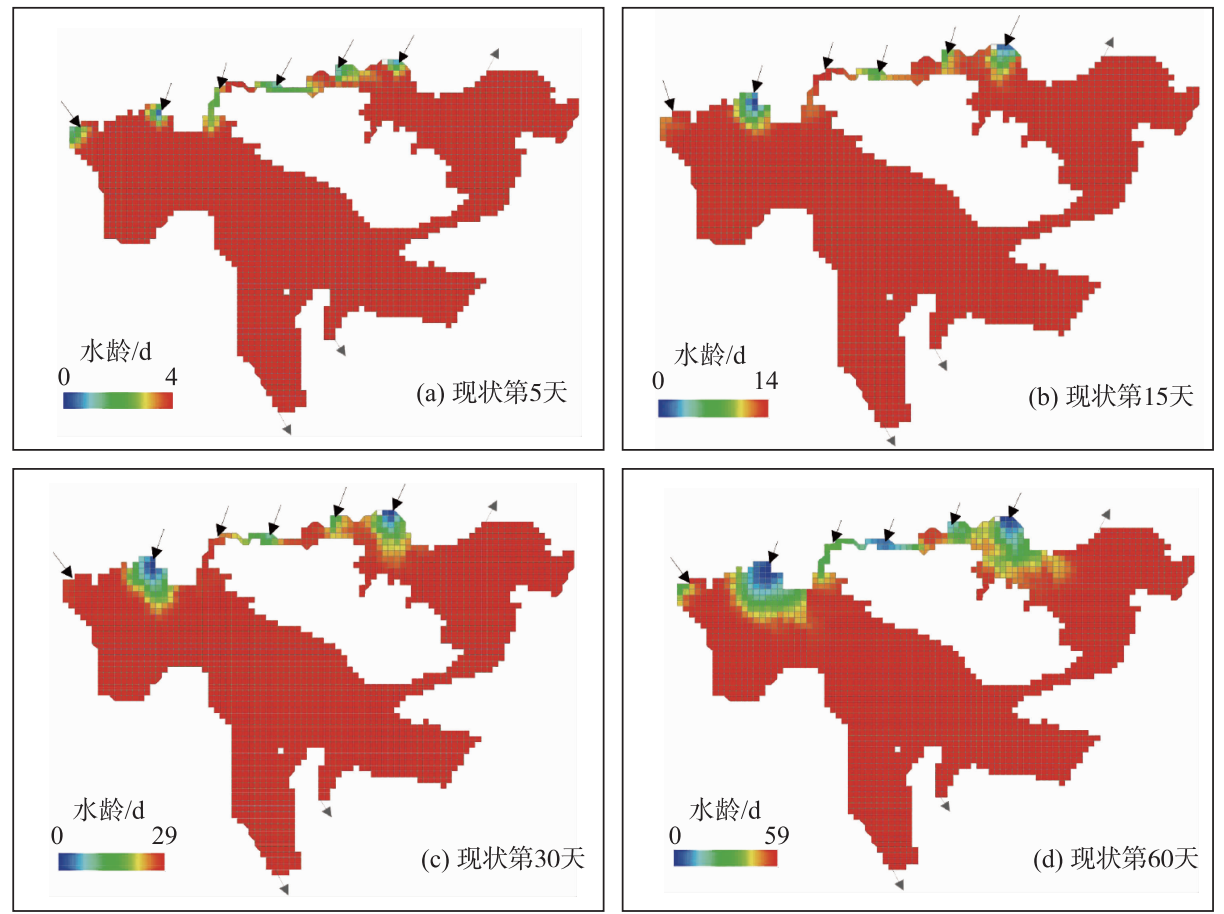

图 6 现状情景水龄时空变化

Fig.6 Current situation water age spatiotemporal variation
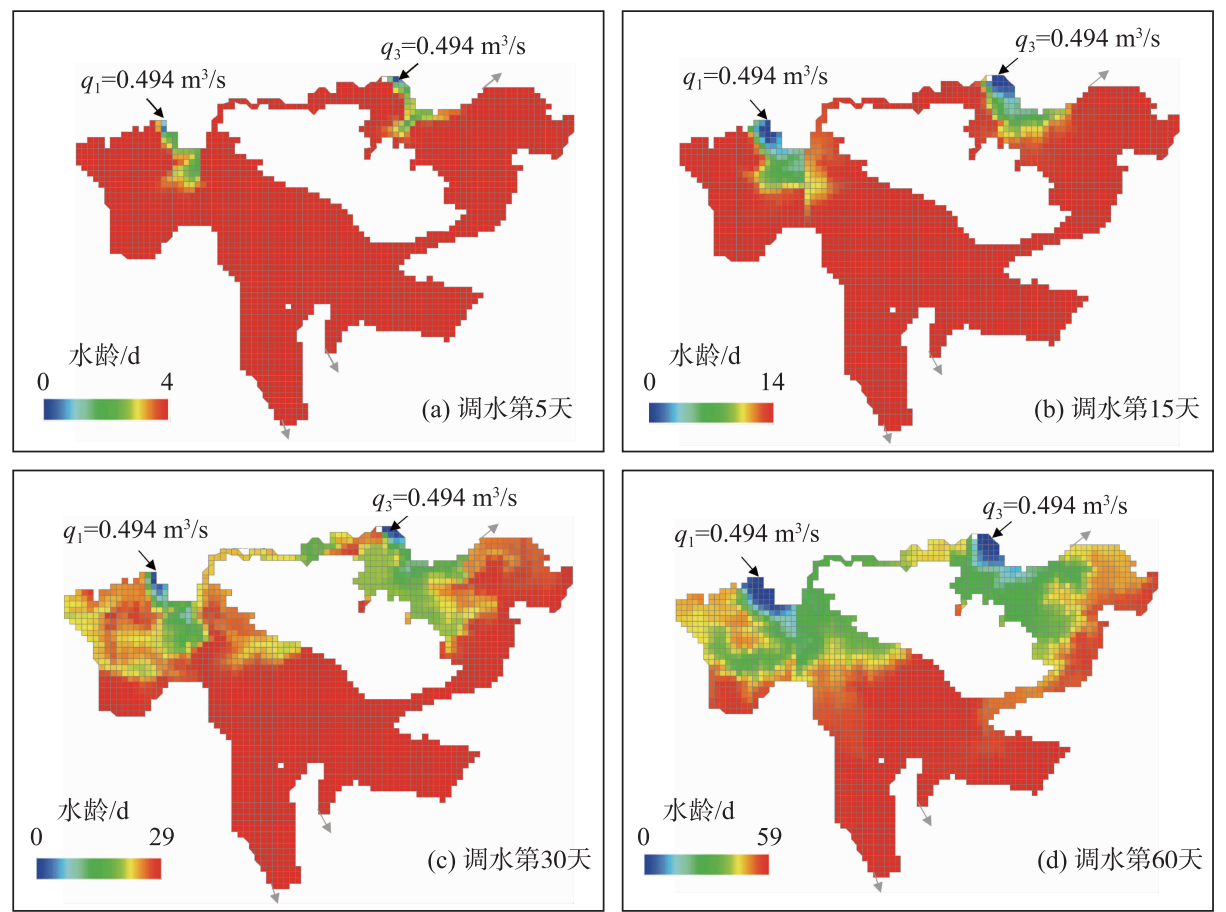

图 7 方案一 (工况 1) 水龄时空变化

Fig.7 Scheme one (working condition 1) water age spatiotemporal variation 

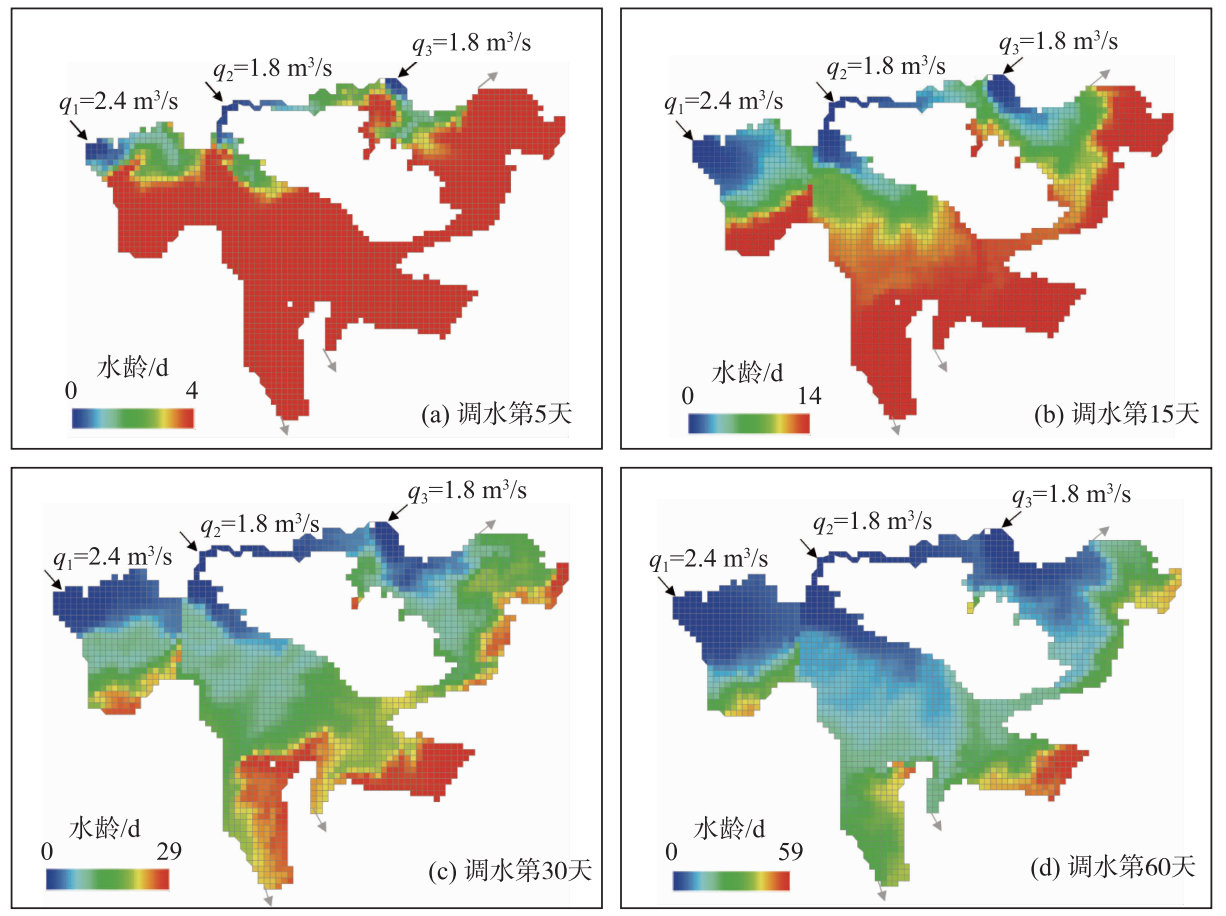

图 8 方案二(工况 5 ) 水龄时空变化

Fig.8 Scheme two (working condition 5) water age spatiotemporal variation
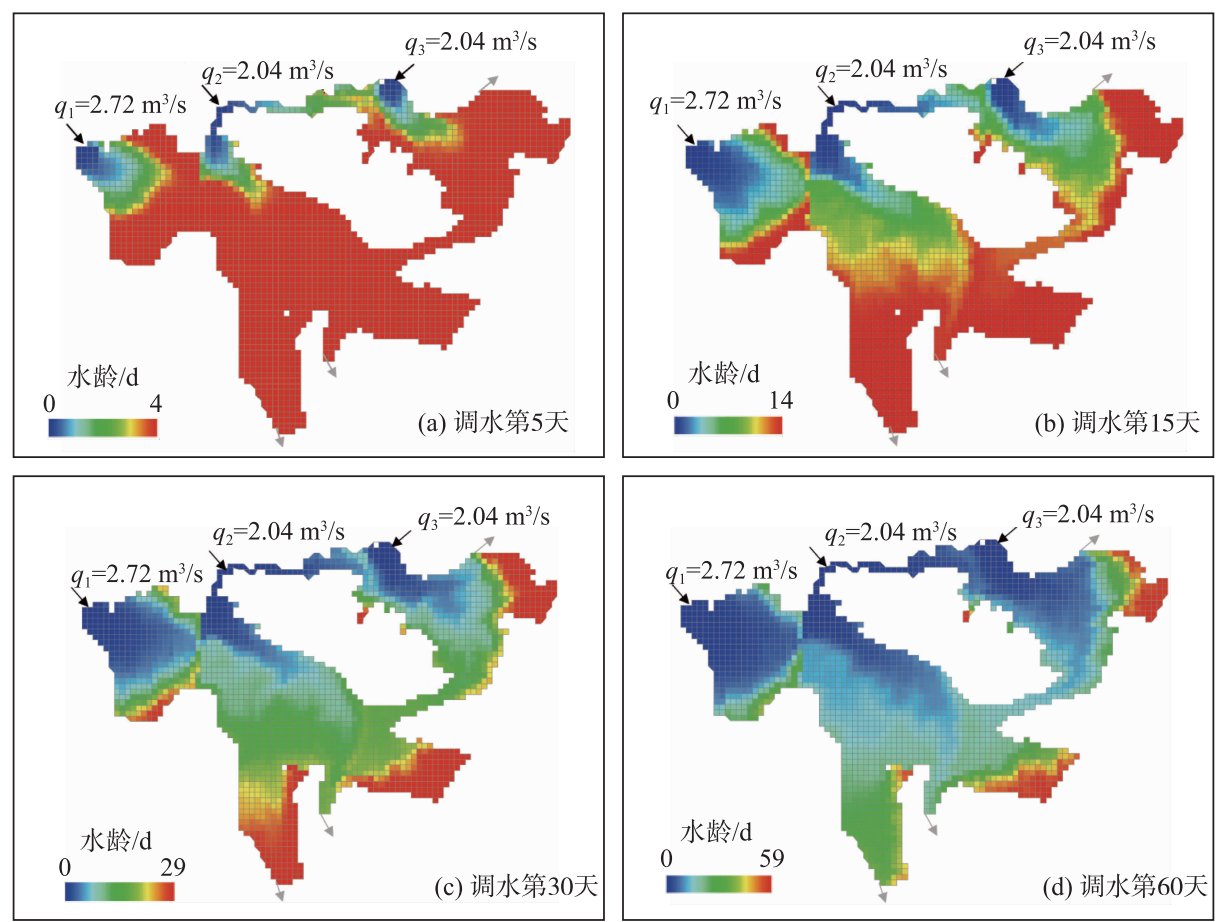

图 9 方案三 (工况 10) 水龄时空变化

Fig.9 Scheme three (working condition 10) water age spatiotemporal variation 
莲湖和仙女湖水体交换速率分别提升了 $58.68 \%$ 和 $61.20 \%$, 说明青莲湖出水口和仙女湖出水口能有效增加 青莲湖和仙女湖的水体交换速率.

\section{4 调水引流工程及湖泊水龄改善的讨论}

基于 EFDC 构建的三维水动力模型对 “引江济星”工程的评估是以水龄为定量评价指标, 同时考虑风 场对湖流运动的影响, 能够准确反映不同引调水方案实施后对星湖水体交换速率的提升效果, 为工程方 案选取、实施及管理提供科学依据, 并已成功应用到蔡子湖 ${ }^{[6]}$ 、鄱阳湖 ${ }^{[8]}$ 、滇池 ${ }^{[10]}$ 、太湖 ${ }^{[22]}$ 等引调水工程 评估中, 但由于湖泊类型不同, 所受风场的影响也有所差异, 导致各研究结果均有所差异. 太湖是大型浅 水湖泊, 其出流人边界明确, 湖边带相对平滑, 风生流在湖流运动中起着至关重要的作用, 在相同点位由 风向引起的水龄差异大于 $100 \mathrm{~d}$, 在不同点位的水龄差异则超过 $150 \mathrm{~d}^{[22]}$. 星湖是小型景观湖泊, 其在人为 布局的影响下呈现形状不规整的特点, 各湖区水体连通性较弱, 在湖湾地区易发生水体滞留形成死水区, 其水动力交换过程主要受到人湖通道布局 (包括流量配比、点位设置、出人湖道数量) 的影响, 受风场影响 较小, 其由风向引起的水龄最大差值为 $34.38 \mathrm{~d}$, 由风向引起的水龄最小差值为 $26.18 \mathrm{~d}$. 引调水工程对湖 泊的影响表现在水质、水动力、透明度、水生生物群落等各个方面, 为得出更为科学客观的引调水方案, 水 龄值不能作为选定调水引流工程的唯一判据, 引调水工程的实施需综合考虑以上指标并结合当地水资源 的配置、引水工程的经济投资 ${ }^{[23]}$ 、对生态环境的开发及影响 ${ }^{[24]}$ 等进行综合评定. 在论证调水引流方案可 达性、合理性、可行性的过程中, 本文以减小水龄为主要目标的同时, 综合了调水引流方案在实施过程中 的经济投资、生态占地和开发, 最终拟定方案二为最优调水引流方案, 方案二 (西江引水) 和方案三 (西江 引水+北岭山来水) 情景下星湖平均水龄分别为 33.30 和 $30.62 \mathrm{~d}$, 方案三水龄略小于方案二,但方案三需 新建更多的箱涵、集水池、输水管道, 其中涉及对北岭山森林资源的开发, 相较于方案二, 方案三需多投资 近四千万(其中不含征地、拆迁费用).

\section{3 结论}

“引江济星”工程对星湖的影响可通过水龄的时空分布来体现, 本文基于 EFDC 构建了星湖三维水动 力一风场耦合模型, 研究了星湖水龄的季节性分布特征、不同人湖通道布局和不同流量配比下星湖的水龄 时空分布及 “引江济星”工程和风场对湖泊水龄时空分布的影响. 模拟结果表明, “引江济星”工程对星湖水 龄时空分布有十分重要的影响, 风场对星湖水龄的时空分布影响较小.

1) 星湖水龄分布存在季节和空间差异. 季风作用有效地降低了星湖平均水龄,秋季季风对水体交换影 响最显著; 风场促进了中心湖、青莲湖、仙女湖的水体交换, 抑制了波海湖的水体交换, 对于星湖整体而言, 由风向为南东南风时水龄最小.

2) 波海湖的最优人湖线路河道为外坑, 且波海湖人流流量: 中心湖人流流量: 仙女湖人流流量最优分配 比为 $4: 3: 3$. 综合比较 “引江济星”工程的不同方案的平均水龄, 结合考虑调水引流综合效益、经济投资、生态 开发和和占地等成本, 方案二 (工况 5 , 引西江水由外坑、雨水口和石牌坑人星湖) 为最优调水引流方案. 规 划拟建的青莲湖出水口和仙女湖出水口能有效加快青莲湖东北部和仙女湖东南部的水体交换速率.

3) 针对形状不规则的城市内湖,在湖心大面积敞风区, 风场是驱动湖体环流的主导因素, 在岸线复杂的 湖湾区,出人湖口布局及风场风向的一致性是影响湖区水龄的主控因素.

\section{4 参考文献}

[ 1 ] Gong R, Xu J, Xu LG et al. Study on hydrodynamics in urban landscape lake based on EFDC. Environmental Engineering , 2015, 33(4) : 58-62, 91. DOI: 10.13205/j.hjgc.201504013. [龚然, 徐进, 徐力刚等. 基于 EFDC 城市景观湖 泊水动力模拟研究. 环境工程, 2015, 33(4) : 58-62, 91.]

[ 2 ] $\mathrm{Wu} \mathrm{X,} \mathrm{He} \mathrm{J.} \mathrm{The} \mathrm{application} \mathrm{of} \mathrm{EFDC} \mathrm{model} \mathrm{in} \mathrm{the} \mathrm{design} \mathrm{of} \mathrm{ecological} \mathrm{water} \mathrm{supplement} \mathrm{project} \mathrm{for} \mathrm{urban} \mathrm{landscape} \mathrm{wa-}$ ter-case study of thegreenlake in Kunming. Environmental Protection Science, 2019, 45 (1): 73-78. [吴雪, 何佳. EFDC 模型在城市景观水体生态补水工程设计中的应用一一以昆明市翠湖为例. 环境保护科学, 2019, 45(1): 73-78.]

[ 3 ] Li YP, Acharya K, Yu ZB. Modeling impacts of Yangtze River water transfer on water ages in Lake Taihu, China. Ecologi- 
cal Engineering, 2011, 37(2) : 325-334. DOI: 10.1016/j.ecoleng.2010.11.024.

[ 4 ] Gao XP, Xu LP, Zhang C. Estimating renewal timescales with residence time and connectivity in an urban man-made lake in China. Environmental Science and Pollution Research, 2016, 23 (14): 13973-13983. DOI: 10. 1007/s11356-0166569-5.

[ 5 ] Gao XP, Chen YY, Zhang C. Water renewal timescales in an ecological reconstructed lagoon in China. Journal of Hydroinformatics, 2013, 15(3) : 991-1001. DOI: 10.2166/hydro.2013.136.

[ 6 ] Wang Z, Fan ZY, Yang ZY et al. Effects of water diversion project from the Yangtze River to Huaihe river on the water age distribution of Lake Caizi, Anhui Province. J Lake Sci, 2018, 30(6) : 1576-1586. DOI: 10.18307/2018.0609. [王钟, 范中亚, 杨忠勇等. “引江济淮”工程对安徽菜子湖水龄分布的影响. 湖泊科学, 2018, 30(6) : 1576-1586. ]

[ 7 ] Huang CL, Li X, Sun YY. Water age distribution of the Lake Taihu and impact of the Yangtze River to Lake Taihu Water Transfer Project on the water age. J Lake Sci, 2017, 29(1) : 22-31. DOI: 10.18307/2017.0103. [黄春琳, 李熙, 孙永 远. 太湖水龄分布特征及“引江济太”工程对其的影响. 湖泊科学, 2017, 29(1): 22-31.]

[ 8 ] Zhang SX, Xu XF, Xu X et al. Seasonal variations of water age in Lake Poyang. J Lake Sci, 2018, 30( 1) : 199-210. DOI : 10.18307/2018.0120. [张素香, 许新发, 徐兴等. 鄱阳湖水龄季节性变化特征. 湖泊科学, 2018, 30(1): 199-210.]

[ 9 ] Qi W, Li YP, Wang Y et al. Control and optimization scheme of Tianjing lake hydrodynamics based on EFDC model. Water Resources and Power, 2015, 33(1): 47-51. [戚文, 李一平, 王芗等. 基于 EFDC 模型的天镜湖水动力优化调控 方案研究. 水电能源科学, 2015, 33(1): 47-51.]

[10] Zhang XL, Zou R, Wang YL et al. Is water age a reliable indicator for evaluating water quality effectiveness of water diversion projects in eutrophic lakes? Journal of Hydrology, 2016, 542 : 281-291. DOI: 10.1016/j.jhydrol.2016.09.002.

[11] You AJ, Wu ZY, Han ZC et al. Spatial and temporal distributions and variations of nutrients in the West Lake, Hangzhou, after the implementation of integrated water management program (1985-2013). J Lake Sci, 2015, 27(3): 371377. DOI: 10.18307/2015.0301. [尤爱菊, 吴芝瑛, 韩曾萃等. 引水等综合整治后杭州西湖氮、磷营养盐时空变化 (1985-2013 年). 湖泊科学, 2015, 27(3) : 371-377.]

[12] Gao XP, Xu LP, Zhang C. Modelling the effect of water diversion projects on renewal capacity in an urban artificial lake in China. Journal of Hydroinformatics, 2015, 17 (6) : 990-1002. DOI: 10.2166/hydro.2015.004.

[13] Zhou LP, Huang JC, Guo CH et al. Study on the plant disposition of Xinghu national wetland park. Journal of Zhaoqing University, 2015, 36(2) : 49-53. [周丽萍, 黄建昌, 郭春华等. 星湖国家湿地公园植物配置研究. 肇庆学院学报, $2015, \mathbf{3 6}(2): 49-53$.]

[14] Zhang YF, Wang YL, Wang L. EFDC overview and application analysis. Environmental Impact Assessment, 2015, 37 (3) : 70-72, 92. DOI: 10.14068/j.ceia.2015.03.018. [张以飞, 王玉琳, 汪靓. EFDC 模型概述与应用分析. 环境影响评 价, 2015, 37(3): 70-72, 92.]

[15] Liu XM, Li JQ, Dou XM et al. The application and advance of environmental fluid dynamics code( EFDC) in estuarine water environment. Environmental Science \& Technology, 2011, 34(S1)：136-140, 360. [刘夏明, 李俊清, 豆小敏等. EFDC 模型在河口水环境模拟中的应用及进展. 环境科学与技术, 2011, 34 (S1) : 136-140, 360. ]

[16] Song WW, Xu Q, Fu XQ et al. EFDC simulation of fishway in the diversion dahaerteng river to Danghe reservoir, China. Ecological Indicators, 2019, 102: 704-715. DOI: 10.1016/j.ecolind.2019.03.025.

[17] Li YP, Tang CY, Wang C et al. Assessing and modeling impacts of different inter-basin water transfer routes on Lake Taihu and the Yangtze River, China. Ecological Engineering, 2013, 60 : 399-413. DOI: 10.1016/j.ecoleng.2013.09.067.

[18] Jiang CB, Zhang MW, Yang XL. Water quality evaluation for the Hengshui Lake wetland in Northern China. Journal of Tsinghua University:Science and Technology, 2010, 50(6): 848-851. [江春波, 张明武, 杨晓蕾. 华北衡水湖湿地的水 质评价. 清华大学学报: 自然科学版, 2010, 50(6): 848-851.]

[19] Dai J, Liu S, Han JF et al. Study on river water quality response relationship under multi scenario change of pollution load. China Environmental Science, 2018, 38(2): 776-783. [戴君, 刘硕, 韩金凤等. 污染负荷多情景变化下河流水质响 应关系研究. 中国环境科学, 2018, 38(2): 776-783.]

[20] Yang Q. Water environment dynamics simulation research and emergency water pollution incidents based on EFDC-Miyun Resorvior as an example[Dissertation]. Beijing: China University of Geosciences (Beijing), 2014. [杨倩. 基于 EFDC 的 密云水库水环境及应急处理模型研究 [学位论文]. 北京: 中国地质大学 (北京), 2014.] 
[21] Deleersnijder E, Campin JM, Delhez EJM. The concept of age in marine modelling: I. Theory and preliminary model results. Journal of Marine Systems, 2001, 28(3/4) : 229-267. DOI: 10.1016/S0924-7963(01) 00026-4.

[22] Xu RC, Pang Y, Hu ZB et al. Relationship between water age and hydraulic residence time in Taihu Lake and parameter sensitivity. Water Resources Protection, 2020, 36(3) : 34-39. [胥瑞晨, 逢勇, 胡祉冰等. 太湖水龄与水力停留时间关 系及参数敏感性. 水资源保护, $2020,36(3): 34-39$. ]

[23] Hao WB, Tang CY, Hua L et al. Effects of water diversion from Yangtze River to Taihu Lake on hydrodynamic regulation of Taihu Lake. Journal of Hohai University: Natural Sciences, 2012, 40(2) : 129-133. [郝文涁, 唐春燕, 滑磊等. 引江 济太调水工程对太湖水动力的调控效果. 河海大学学报: 自然科学版, 2012, 40(2): 129-133.]

[24] Wang ZQ. Project of water diversion to north of Zhejiang province[ Dissertation]. Hangzhou: Zhejiang University, 2006. [王贞琴. 浙北引水工程方案选优综合评价 [学位论文]. 杭州 : 浙江大学, 2006.]

[25] Lu HM, Zou Y, Feng HL. Analysis and enlightenment of eco-environmental impact of typical water diversion and transfer projects at home and abroad. Water Resources Planning and Design, 2018, (12):88-92, 166. [陆海明, 邹鹰, 丰华丽. 国内外典型引调水工程生态环境影响分析及启示. 水利规划与设计, 2018, (12): 88-92, 166. ] 